University of Nebraska - Lincoln

DigitalCommons@University of Nebraska - Lincoln

Marketing Department Faculty Publications

Marketing Department (CBA)

1994

\title{
Dual Diffusion: Analysis and Implications for Sales Force Management
}

\author{
Madhavan Parthasarathy \\ University of Nebraska-Lincoln, madhavan.parthasarathy@ucdenver.edu \\ Ravipreet S. Sohi \\ University of Nebraska-Lincoln, ravisohi@unl.edu \\ Ronald D. Hampton \\ University of Nebraska-Lincoln, ron@unl.edu
}

Follow this and additional works at: https://digitalcommons.unl.edu/marketingfacpub

Part of the Business Administration, Management, and Operations Commons, Marketing Commons, Sales and Merchandising Commons, and the Strategic Management Policy Commons

Parthasarathy, Madhavan; Sohi, Ravipreet S.; and Hampton, Ronald D., "Dual Diffusion: Analysis and Implications for Sales Force Management" (1994). Marketing Department Faculty Publications. 19. https://digitalcommons.unl.edu/marketingfacpub/19

This Article is brought to you for free and open access by the Marketing Department (CBA) at DigitalCommons@University of Nebraska - Lincoln. It has been accepted for inclusion in Marketing Department Faculty Publications by an authorized administrator of DigitalCommons@University of Nebraska - Lincoln. 
The authors would like to thank James W. Gentry, Robert A. Mittelstaedt, and anonymous reviewers of the Journal of Marketing Theory and Practice for their valuable comments and suggestions.

\title{
Dual Diffusion: Analysis and Implications for Sales Force Management
}

\author{
Madhavan Parthasarathy \\ University of Nebraska-Lincoln \\ Ravipreet S. Sohi \\ University of Nebraska-Lincoln \\ Ronald D. Hampton \\ University of Nebraska-Lincoln
}

\begin{abstract}
Retail resistance to an innovation can hamper its supply to consumers, thereby influencing product adoption behavior. Given this, a dual diffusion process consisting of both retail and consumer adoption is more appropriate in today's dynamic marketplace. Sales emphasis by manufacturers can strongly influence retail and consumer adoption behaviors, which would be reflected in the shapes of their respective patterns. In this paper, we examine the nature of retail adoption and its impact, both positive and negative, on consumer adoption. Following this, we present a strategic framework that lays out the sales management implications of the dual diffusion process.
\end{abstract}

\section{INTRODUCTION}

Innovation is the soul of evolution and therefore the diffusion of innovations should be of central importance to any field of study, including marketing, that attempts to study human development, evolution and the improvement of quality of life. The conventional diffusion of innovations framework (and its close cousin the product life-cycle concept) provides a useful, though restrictive, theoretical base for strategic decision making concerning the introduction and subsequent adoption of new products. Perhaps, the most restrictive assumption that underlies these two concepts (see Gatignon and Robertson 1985 and Rink and Swan 1979 for 
respective reviews) is the presumption that the innovation is adequately available to potential adopters. Existing literature supports the contention that the diffusion framework is a demand driven concept that ignores the strong impact of supply restrictions on product adoption (Lambkin and Day 1989; Mahajan and Muller 1979; Simon and Sebastian 1987). The assumption of adequate supply of an innovation can be unrealistic even in the heterogenous American marketplace because as retailers gain more power, they can choose to be selective about the kinds of new products they stock on their shelves (AdWeek's Marketing Week 1986; Farris, Oliver and de Kluyver 1989; Felgner 1989).

The diffusion paradigm can be viewed as a theory of communications that examines the role of both external communication (influence from outside the social system) and word-ofmouth communication in influencing product adoption behavior among members of a society. Unlike other forms of communication, personal selling involves a "two way" interaction between the seller and the buyer. It can therefore, be considered both a form of external communication (e.g., providing information about a product to potential consumers) as well as a trigger for word-of-mouth influence (e.g., providing opinion leadership). In addition, personal selling by manufacturers can help overcome retail resistance to an innovation. Thus, the sales force can play an important role in influencing the overall adoption pattern of an innovation within a society. Therefore the study of personal selling as a form of communication should be central to the study of product adoption and diffusion.

For a new product to be adopted by individuals in a social system, it has to go through a "dual diffusion" process, diffusing first through the retailers and then the end users. The manufacturer' s sales force plays an important role in facilitating the dual diffusion process. It can directly influence adoption by retailers as well as ultimate consumers. Similarly, the retail sales force can also play a strong role in influencing consumer adoption decisions. The purpose of this paper is to describe the concept of dual diffusion and discuss its implications for sales force management. We begin by discussing the dual diffusion concept. Then we develop a managerial framework with four possible scenarios of interaction between retail and consumer promotion. We describe the scenarios and discuss the role of the sales force in each case. Although we allude to the retail sales force where appropriate, our primary sales focus is from a manufacturer's viewpoint. We con elude with the implications for sales force management.

\section{Dual Diffusion}

As mentioned, the assumption of adequate supply that is necessary for the S-shaped diffusion pattern to materialize (see Rogers 1983), may be questionable in today's rapidly changing marketplace. If, for whatever reasons, supply restrictions exist such that demand for a product by potential adopters exceeds its supply, then some potential adopters have to do without the innovation. If one assumes, purely for illustrative purposes, that no repeat purchase occurs, then the shape of the adoption curve will reflect the shape of the supply curve. This view is endorsed by Wind and Mahajan (1987). In such a situation, it is plausible that the conventional S-shaped diffusion curve will not materialize. Such a hypothetical situation is graphically represented in Figures $1 \mathrm{~A}$ and 1B. Figure $1 \mathrm{~A}$ is a traditional diffusion curve for a hypothetical product, with no supply restrictions. Figure 1B recasts Figure 1A given a supply restriction of 1,000 units per time period starting at around time period 4. Assuming that repeat purchase does not occur and that 
demand beyond this point exceeds 1,000 units per time period (as represented in Figure 1A), the shape of the adoption pattern in Figure 1A changes to the pattern in Figure 1B.

In sum, a prerequisite for consumer adoption of a product is its availability. Adequate availability of a product depends on its adoption by channel intermediaries, especially retailers. If for some reason the intermediaries do not adopt a product, then it is impossible for consumers to purchase the product even if they really want it. Hence, adoption of a product by channel intermediaries must precede its adoption by consumers. We refer to this phenomenon, where a product must first be adopted by channel members and then by consumers, as dual diffusion.

From a communications perspective, the dual diffusion phenomenon implies a two-layered interactive communication system. In this context, a manufacturer's sales force has the dual task of influencing both retail as well as consumer adoption. At least initially, the main sales focus has to be oriented toward the retailer since retail acceptance precedes consumer adoption. Once a sufficient number of retailers have adopted the product, more sales emphasis may be directed at consumers either directly or through cooperative effort between the manufacturer and the retailer. The retail sales force,

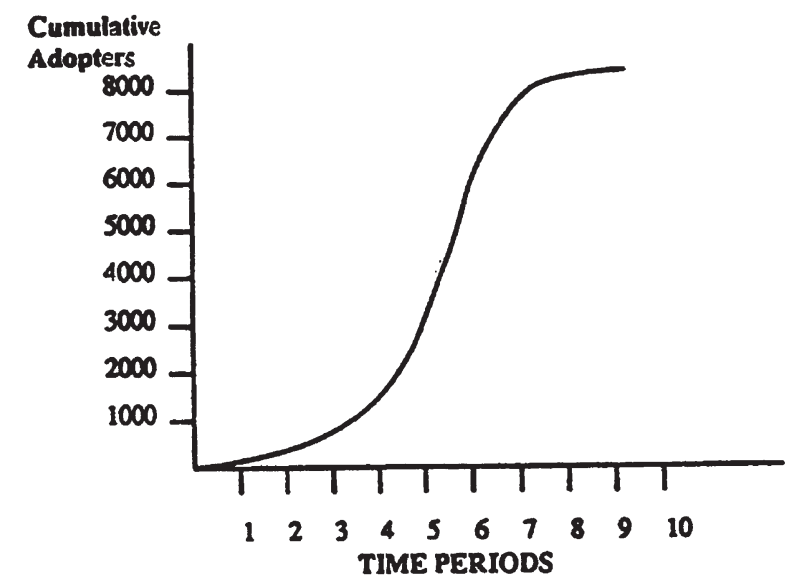

Figure 1A. A Typical Diffusion Pattern for a Hypothetical Product. on the other hand, has the sole task of influencing consumer adoption. However, since most retailers carry several different product lines, often manufactured by . different firms, their sales focus is likely to be broad, rather than deep, unless the manufacturer of a particular product provides special incentives that act as motivators for the retail sales force to promote specific products. Thus, a manufacturer's sales emphasis is likely to be intense and vertical (i.e., influence is directed at retailers and consumers) while a retailer's sales emphasis is likely to be more horizontal (i.e., across several manufacturers) and less intense (i.e., less emphasis on a particular product) in nature.

At this juncture it may be appropriate to relate the dual diffusion concept to one of the more widely cited models of the adoption process, namely the Klonglan and Coward (1970) model. A pictorial depiction of this model is shown in Figure 2. It is important to distinguish between the terms "symbolic adoption" and "use adoption" used in the model. Symbolic adoption concerns the decision to adopt, based on information and evaluation (i.e., attitudes). Use adoption is the actual act of adoption (i.e., behavior). It is the final step in the adoption-decision process. Some individuals may symbolically reject an innovation by deciding on the basis of available infor-

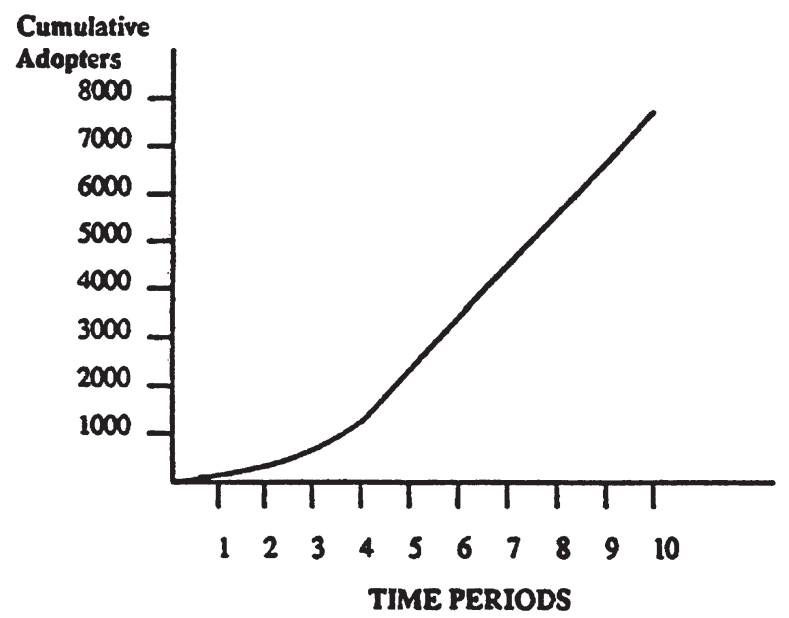

Figure 1B. Diffusion Pattern Given a Supply Restriction of 1000 Units per Time Period. 
mation, that the innovation is not appropriate for them. Others may symbolically accept the innovation and display a desire to try the new offering. Thus, an individual who becomes aware of a new cake mix may evaluate and decide that the product is suited to his/her needs (symbolic adoption). She/he may then purchase a package of the product during the next grocery trip (trial). If the product meets or exceeds prior expectations, she/he may adopt it on a permanent basis (use adoption). But if an innovation is not available in adequate quantities, perhaps due to its rejection by channel intermediaries, there may be a large number of symbolic adopters who do not have the opportunity to proceed to the trial and/or use adoption stage. Therefore, the adoption of a product by channel members is essential for potential consumers to proceed from symbolic adoption to the trial stage.
The Klonglan and Coward (1970) model presumes cognitive processing on behalf of the potential adopter (Mittelstaedt et al. 1976). It does not take into account the role of interpersonal communication and social influence in product adoption, even though research lends support to the contention that both these factors often have crucial roles in behavioral decision making (Ajzen and Fishbein 1980; Fishbein and Ajzen 1975; Rogers 1983; Rosen and Olshavsky 1987). While symbolic adoption may be considered a judgment task, use adoption is synonymous with a choice task. Apart from judgment, choice is guided by risk and accountability (Einhorn and Hogarth 1981; Tetlock 1991). Therefore, it seems logical that the Klonglan and Coward (1970) model, which disregards the existence of social influence in product adoption, is valid for those adopting entities whose adoption deci-

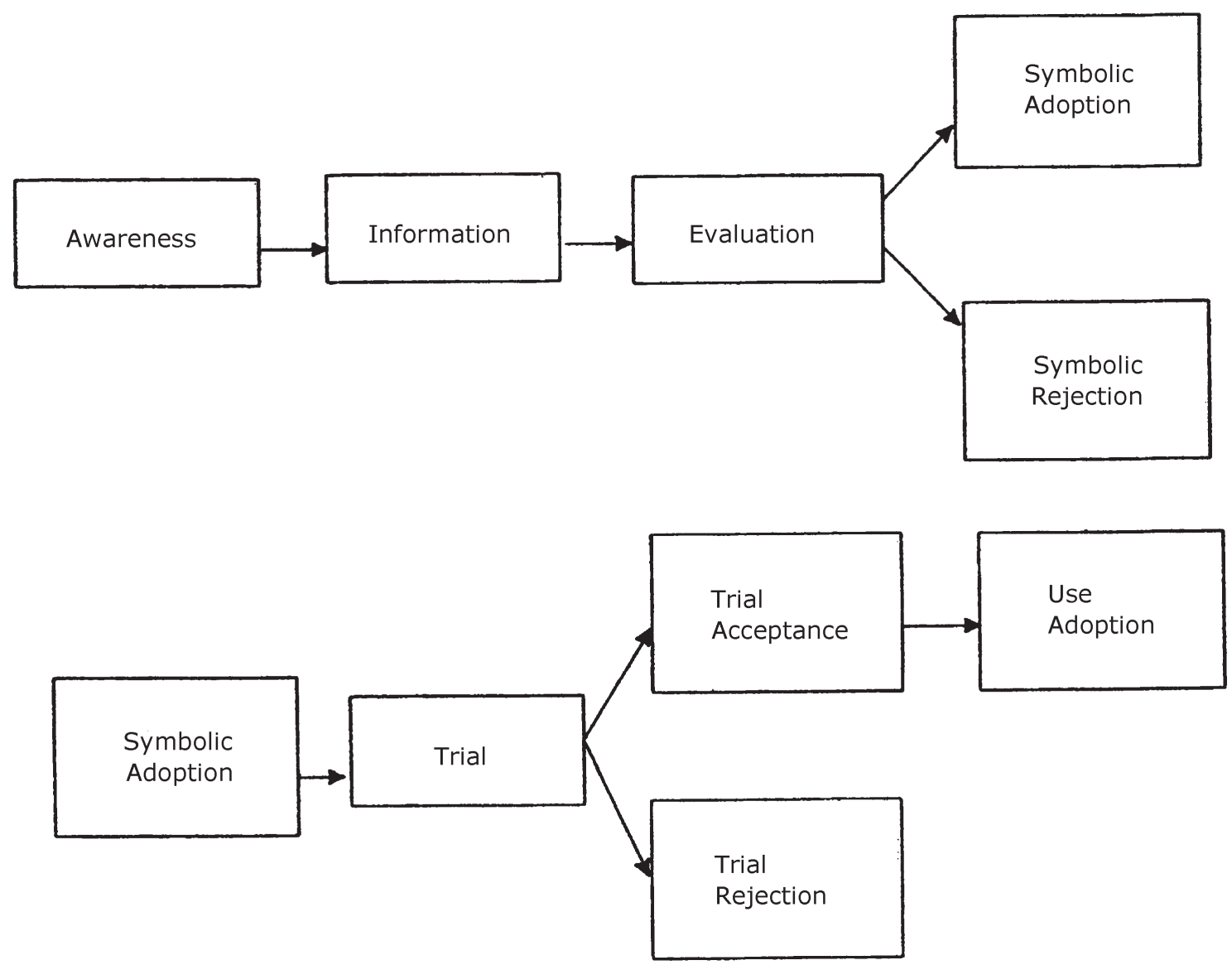

Figure 2. Klonglan and Coward Symbolic Adoption Process Model. 
sions are primarily guided by external influence and communication. Using the classification proposed by Bass (1969), this model is especially applicable to innovators (those individual $\mathrm{s}$ whose adoption decision is influenced by external communication) and not imitators (those individual s whose adoption decisions are influenced primarily by word-of-mouth within the social system). The earliest adopters of an innovation, according to Bass (1969), are likely to be innovators.

The analysis presented above leads to an important conclusion: that most innovators' adoption decision, being strongly governed by attitudes and judgment, is generally influenced by symbolic acceptance. Imitators, on the contrary, base their adoption decision primarily on other peoples' opinions and may therefore adopt a product for use even though they may not have symbolically accepted it. Put differently, it appears that imitators are more likely to adopt a product even though they symbolically resisted it to a greater extent than innovators.

\section{Retail Adoption}

Most diffusion literature has focused on consumer adoption. As a result, our knowledge of the consumer adoption process is quite elaborate. However, very little has been written about the shape of the adoption curve of channel intermediaries, even though the role of intermediaries in the consumer diffusion process has been recognized (Hirschman and Stampfl 1980; Midgley 1974). Only a few studies (e.g., Bennett 1987; Rao and McLaughlin 1989) have examined the factors that influence the adoption decision of certain retailers.

There is no reason to believe that the diffusion process for retailers is substantially different from the process for consumers. Studies on organizational adoption of products (e.g., Takada and Jain 1991) suggest that adoption of products by organizations, like that by consumers, follows a sigmoid (S-shaped) pattern. Therefore, it appears that retail adopters can also be placed in categories (e.g., innovators, early adopters, early majority, late majority and laggards) depending on their time of adoption (see Rogers 1983 for more details on this classification). Alternatively, and more appropriately, using the conceptualization proposed by Bass (1969), retail adopters can be broken down into innovators and imitators depending on whether they are primarily influenced by external influence (e.g., the manufacturer' s sales force, promotion efforts, trade discounts etc.) or by communication between retailers within the system. Research lends support to the notion that though homophilous influence (interpersonal communication/ within-group communication) is more predominant among imitators, heterophilous influence (external influence) is common among innovators (Barnett 1953; Granovetter 1973; Rogers 1983). Research also lends support to the contention that innovators have higher incomes, take greater risks and are generally more venturesome than later adopters (Midgley and Dowling 1978; Robertson, Zielinski and Ward 1984; Rogers 1983).

An extension of these research findings to retail adopters implies that the first few retailers to adopt an innovation (i.e., the innovators), are likely to be venturesome and risk taking organizations that can afford to take a loss in case the innovation fails. These organizations are likely to be influenced by external sources. Organizations that adopt later (i.e., the imitators), are likely to be less venturesome and risk prone. Their adoption decisions are likely to be guided more by homophilous pressure-that is, they are likely to wait and watch and adopt a product only if it shows substantial signs of success. As with consumer adoption, the imitators are likely to far outnumber the innovators, leading to an increased rate of adoption once "take off" occurs. 
It seems that the retail adoption pattern mimics the consumer adoption pattern and is therefore (assuming no restrictions), likely to be sigmoid in shape. However, two issues warrant further discussion. First, unlike manufacturers of innovative products, innovative retailers cannot afford to use a skimming strategy because the lead time (the time taken by a competing retailer to offer the same, or similar, product) is very short in the retail business. Thus, an innovative retailer cannot hope to enjoy a substantial period of profitability without attracting competition. Since the risk associated with adopting a new product can be substantial, the number of innovative retailers is likely to be small initially. The retail adoption curve will therefore, feature a rather shallow initial adoption pattern. Second, the slope of this pattern will increase sharply once other imitator retailers jump on the bandwagon and "take off' occurs. Although word-of-mouth communication may not be as strong among retail adopters as among consumer adopters, it is possible for a retailer to monitor a competitor's success with a new product and use such information to make an adoption decision. This is also a form of within group influence which may partially cause the sigmoid shape of the retail adoption pattern. On the whole, it appears that imitating will be far more predominant than innovating (especially since initial risk is high and the benefits are low) causing a sharp kink in the sigmoid pattern once "take off' occurs.

Most diffusion and product life cycle studies (e.g., Rink and Swan 1979) acknowledge the role of price in the adoption-decision process. Retailers who compete primarily on price (e.g., discount retailers) will tend to adopt an innovation when its price declines to a point compatible with their strategy and image. Since price is likely to go down during the later stages of the adoption process, one would expect discount stores and other low price retailers to be later adopters (i.e., imitators). On the other hand, innovating retailers are likely to be large, specialized stores that are capable of absorbing a loss in case the innovation fails. Sales emphasis is likely to be the most predominant (and crucial) during the initial stages of the consumer diffusion process where most consumers are uninformed about the product and where most prospective adopters are innovators who actively seek information about the product. Therefore, innovating retailers, who happen to be large resourceful organizations, are the ones that need maximum support from the manufacturer's sales force.

\section{Interaction Between Retail and Consumer Adoption Behavior}

There seems to exist a two-way cause effect relationship between retailer adoption behavior and consumer adoption behavior. Since consumers cannot possibly adopt a product until the retailer has done so, retail adoption must precede consumer adoption. After the product is made available to consumers, retail adoption is contingent on consumer adoption. This point needs further discussion. If consumer demand for a product does not exist, its adoption by a retailer will surely result in a loss. On the other hand, if consumer demand is strong such that many potential adopters have symbolically accepted the innovation, then it makes good business sense for a retailer to adopt the product to cater to this pre-existing demand. Since consumer adoption increases after "take off," it stands to reason that once this point is reached, it may be lucrative for new retail imitators to adopt the innovation, possibly causing the "take off' of the retail adoption pattern. Thus, it appears that the "take off' in the consumer adoption curve occurs before the "take off" in the retail adoption curve. This may be 
catalyzed by the notion that many retailers may actively promote or "push" a product in order to spur consumer demand, thereby causing its early "take off." This in turn, hastens the "take off' in the retail adoption pattern. Even though retail adoption is a prerequisite to consumer adoption, the former depends on the latter. Therefore, a sales strategy of actively promoting or "pushing" products to consumers during the initial stages of the diffusion process may influence consumer adoption, indirectly influencing future retail adoption.

\section{A Managerial Framework}

We now present a managerial framework consisting of four possible scenarios. This framework, graphically depicted as a $2 \times 2$ matrix in Figure 3 , stems from the preceding discussion regarding the dynamic interaction between retail adoption and consumer adoption. In the figure, retail adoption and resistance are depicted on the vertical axis while symbolic consumer adoption and resistance are depicted on the horizontal axis. We use the term resistance rather than rejection, because even though some retailers and consumers resist an innovation (i.e., form negative attitudes and judgments toward the innovation), they may eventually adopt it (i.e., engage in the very behavior that they resisted). As addressed earlier, it is more likely that imitators, rather than innovators, will engage in such behavior. Thus, it is possible that some consumers adopt a product even though they may have symbolically resisted it. Similarly, the retailer, whose adoption decision is perhaps more economically motivated, may resist an innovation initially but adopt it later if it becomes profitable to do so. In a nutshell, symbolic resistance implies that the adoption rate will be slow, not non-existent. Therefore, it may be possible for some degree of product diffusion to take place even though both the retailer and the consumer resist the innovation. Given this, the four strategic quadrants in Figure 3 are as follows: (1) retail adoption-consumer symbolic adoption, (2) retail adoption-consumer symbolic resistance, (3) retail resistance-consumer symbolic adoption and (4) retail resistance-consumer symbolic resistance. Each of these quadrants is now discussed.

\section{Retail Adoption-Consumer Symbolic Adoption}

In this "best case" scenario, consumer acceptance of the product is strong and the retailer finds it cost beneficial to adopt the product. In such a situation, consumer demand would pull the product from the channel intermediaries making it lucrative for imitator retailers to adopt the product. If consumer demand is met by adequate supply, an S-shaped consumer demand curve, as well as an S-shaped retailer adoption curve exists. This situation would be typical of a successful discontinuous innovation. Due to consumer acceptance of the product, the successful introduction of the product by innovating retailers would soon attract competition. As such, the "take off' for both patterns is likely to occur early. Increased competition may, in turn, lead to a low price strategy being adopted by some retailers (especially discount stores and other low price stores), or a differentiation strategy being adopted by others.

\section{Retailer Adoption-Consumer Symbolic Resistance}

In this scenario the retailer finds it desirable to adopt the product despite the fact that the consumer symbolically resists it. Such a scenario may arise in numerous ways, such as, when the profit margins associated with the product are large, or when the manufacturer offers substan- 
tial trade discounts, or when the product is the retailer's own brand, or when the retailer is convinced, either correctly or erroneously, that consumers' perceptions can be changed with proper promotion strategies. The problem here is to convince consumers to adopt the product by changing their attitudes. The chance of product failure is high during the initial stages. However, if the
Consumer Symbolic Adoption
Consumer Symbolic

Reistance

\section{Retail Adoption}

Retail Resistance

\begin{tabular}{|c|c|}
\hline Characteristics & Characteristics \\
\hline Strong demand pull & Weak demand \\
\hline Strong supply & Strong supply \\
\hline Early "take off" & Late "take off" \\
\hline Strong competition & Strong competition \\
\hline Low price/differentiation & Low price \\
\hline Sales Force Emphasis & Sales Force Emphasis \\
\hline $\begin{array}{l}\text { Writing up and expediting } \\
\text { orders, handling shipping } \\
\text { problems, and serving retail } \\
\text { customers }\end{array}$ & $\begin{array}{l}\text { Creating demand, handling } \\
\text { local advertising, product } \\
\text { displays, searching leads }\end{array}$ \\
\hline Characteristics & Characteristics \\
\hline Strong demand pull & Weak demanà pull \\
\hline Weak supply & Weak supply \\
\hline Later "takeoff" & Very late "take off" \\
\hline Little competition & Little competition \\
\hline High initial price & \\
\hline Sales Force Emphasis & Sales Force Emphasis \\
\hline $\begin{array}{l}\text { Focus on relationships with } \\
\text { retailers, bargaining, } \\
\text { providing incentives to win } \\
\text { shelf space }\end{array}$ & $\begin{array}{l}\text { Trade discounts, creating } \\
\text { demand, handling local } \\
\text { advertising, product displays, } \\
\text { searching leads }\end{array}$ \\
\hline
\end{tabular}

Figure 3. Interaction Between Retail and Consumer Adoption 
initial stage is successfully transcended such that the consumer adoption curve "takes off," then adoption by imitators, who base their decisions primarily on word-of-mouth, is likely to be high. This, in turn may cause the retail pattern also to "take off." In sum, two alternatives exist for this scenario: (1) the product fails, or (2) the product succeeds, such that both the consumer and the retailer adoption patterns display S-shaped patterns. One thing is certain; the time until "take off" (if it occurs) is likely to be much greater than the consumer symbolic adoption-retail adoption scenario.

\section{Retailer Resistance-Consumer Symbolic Adoption}

This is the classic situation in which resistance in retail adoption of the product causes demand to exceed supply. In this scenario, an otherwise normal S-shaped consumer adoption curve is stifled by inadequate availability of the product due to retail resistance. This situation may arise under any of the following circumstances: (1) the product is not very profitable to stock, (2) the product is too large and/or cumbersome to stock, or (3) the product is illegal. Each of these circumstances is more likely to occur during the early stages of the diffusion process than in the later stages. Traditional economic theory suggests that the most rational action for the few retailers who adopt the product is to increase price to the point where demand equals supply.

\section{Retailer Resistance-Consumer Symbolic Resistance}

In this scenario, where both the retailers and the consumers resist the innovation, the chances of product failure are the greatest. First, there is no consumer demand to pull the product from the channel intermediaries. Second, the product is not feasible in terms of costs or risks for the retailer to adopt and therefore, the retailer is unlikely to engage in actively pushing the product to potential consumers. Finally, the potential consumers are likely to be extremely price sensitive to the product, nullifying any price skimming strategies that may otherwise have been feasible. Given this, there will be relatively few adopters at both the retail and consumer levels. As a result, the probability of product failure is likely to be the greatest among all the scenarios.

\section{The Role of the Manufacturer's Sales Force}

The manufacturer's sales force plays an important role in the dual diffusion process. When an innovation is introduced in the market, communication from the manufacturer is essential for educating the retailers and the end users. While advertising may be helpful, some communication tasks are performed better by face-to-face selling. Such communication tasks may include providing large amounts of complex information about the new product, adapting promotional appeals to meet the needs of specific target segments and convincing the retailers and end users about the benefits of adopting the innovation. In addition to communication, a salesperson engages in a number of activities, such as, servicing the product, servicing the account, managing information and assisting in distribution (see Moncrief 1986). The relative importance of each activity varies between the four scenarios.

In the best case, when a product is readily accepted by both the retailers and the consumers, the emphasis of the sales force is on order taking and service. The salespeople are generally involved in writing-up orders, expediting orders, 
handling back orders, handling shipping problems and finding lost orders. In addition, they service the customer by stocking shelves, setting up displays and taking inventory. The retailers expect an adequate supply of the product, but at the same time want to minimize their inventory holding costs. Frequency of contact and information management become very important under such circumstances.

In the second scenario, when the retailers adopt the product, but consumers have some symbolic resistance, the sales force can complement the role played by advertising and sales promotion in creating a demand for the product at the consumer level. Salespeople can assist by handling local advertising as well as setting up product displays and information booths. They can also assist by seeking leads and following up on behalf of the retailer. A typical example is that of Black and Decker which introduced the "Dewalt" line of industrial power tools targeted toward the professional construction workers. According to a Dewalt Sales Manager, this line won quick acceptance at the retail level, but faced initial resistance from the construction workers who favored the Makita brand of power tools. To overcome this resistance, the Dewalt sales force organized "tool-gate parties" where salespeople would drive a van to a construction site and demonstrate their line of products. Any leads and orders generated were passed on to the local Dewalt dealer.

The third possible scenario is when the consumers symbolically adopt a product, but the retailers show some resistance. In such a situation, the selling function assumes primary importance and the manufacturer can use a "push strategy" to encourage the retailers to stock the product. Under such a strategy, the salespeople can offer a wide range of inducements to the retailer, such as, larger-than-average margins, various trade sales promotion offerings, cooperative advertising programs, sales aids and point of purchase materials (Churchill, Ford and Walker 1992, p. 123).

Also, when salespeople are selling multiple product lines to a retailer who is their existing customer, they can capitalize on their relationship and enhanced bargaining power (due to handling multiple products) to sell a new product and win shelf space. Sometimes, the salespeople may be faced with a situation where a retailer resists a new product even after some other retailers have adopted it. In such cases, the salespeople can show the resisting retailer the success that the innovative retailers are enjoying with the product. Perhaps, the retailer may be able to see the competitive disadvantage of resisting.

In addition to using a push strategy with existing retailers, the salespeople have to look for additional outlets for their product. This may require additional sales planning, search for new leads, calls on potential accounts and sales presentations. Given the costs associated with these activities, the sales force may have to practice some form of niche selling, in which the salespeople would have to become experts in the operations and opportunities associated with a select target market. In the extreme case, where the retailers do not adopt the product despite the selling effort, the sales force may have to circumvent the retailer and sell directly to the end-user.

In the final scenario, where there is resistance from both the consumers and the retailers, there are going to be relatively few adopters initially. One possible avenue to stimulate adoption may be for the manufacturer to initially offer substantial trade discounts to make it fruitful for retailers to adopt and push the product. In such a case the same sales force strategies applicable in the retail adoption-consumer symbolic resistance may be effectively used. This strategy would certainly be augmented by heavy informationbased promotion directed at the consumers in order to create demand. 


\section{IMPLicATIONS For SALES Force}

\section{Management}

The preceding discussion illustrates the role of the sales force in the dual diffusion process. In order to diffuse the innovation successfully, the salespeople have to be well . trained and thoroughly informed about the uses and benefits of the new product. They must also be willing to spend adequate time with the customers to ensure thorough understanding and proper use of the product. For the sales managers, it implies that the training programs of the salespeople have to be carefully developed and strongly emphasized. It also implies that the sales managers need to devote careful attention to sales planning, so that a sufficient number of salespeople are available to allow for proper coverage (Davis and Webster 1968, p. 220). There may be regional variations in the diffusion process due to differences in market characteristics. This can lead to substantial differences in the productivity of the salespeople. From a management perspective, it implies that the sales managers need to consider these differences when developing sales plans and evaluating the performance of the salespeople.

When influential retailers adopt a new product, the other retailers tend to follow suit, either by example, or due to economic and competitive pressure. This implies that the sales managers need to establish strong relations with the influential retailers and develop strategies that appeal to their norms. For example, when dealing with large corporate chains like Walmart and Safeway, some manufacturers have had to put more money into trade promotions (such as one time slotting fee), to gain shelf space for the new products (Taylor 1986). Other firms, such as Campbell Soup have regionalized their marketing and sales efforts and come out with products that cater to local tastes, making them more attractive to the large retailers (Saporito 1991).
At times, when the influential retailers become increasingly powerful, sales mangers have to devise strategies to offset this bargaining power. Some manufacturers have consolidated their sales forces across SBUs or divisions to coordinate promotion efforts for their various products and provide a strong front to the retailers. This has enabled them to use their strong and well established products to gain leverage for their new products. For example, when Nabisco introduced Almost Home cookies, it authorized its integrated sales force to offer a 10 percent discount till the end of the year, on any cookie or cracker promoted by the company, to all retailers who were willing to give Almost Home cookies four feet of retail shelf space (Taylor 1986).

\section{Conclusions}

This presentation is just a beginning to more detailed and, perhaps, empirical research concerning the crucial and growing, role of retailers and the sales force in product adoption. However, we would like to point out some limitations of this work. First, this paper stresses dual diffusion for the primary purpose of illustrating the importance of retailers in the diffusion process. One may argue, with some justification, that a multiple diffusion situation may occur in some situations whereby different layers of diffusion (e.g., adoption by wholesalers, retailers and then consumers) may be more realistic. We contend that the dual diffusion concept would provide the basic underlying framework for more complex studies in that multiple diffusion would be a straightforward extension of dual diffusion. Second, the underlying presumption of the framework presented in this paper, and indeed that of diffusion of innovations theory in general, is that the innovation being diffused is at least to some extent discontinuous. For contin- 
uous innovations, this framework, as most conventional diffusion frameworks, may require modification.

Future research that addresses the changes that have taken place in the marketplace over the past two decades, e.g., growing retail power, globalization of markets and communications, direct marketing, growth in interactive media and their effects on diffusion of innovations and sales management would be both timely and appropriate. The conventional diffusion framework still exists unchanged as it did twenty years ago while social systems, supply/ demand relationships, the nature of competition and adoption behavior of people around the world have changed remarkably. Incorporating these changes in our theoretical understanding of the adoption of new products will no doubt improve managerial decision making in addition to enhancing theoretical advancement.

\section{REFERENCES}

“The New Power of Retailers: Assessing Retailers' Hold On the Manufacturers (1986)," AdWeek's Marketing Week, 27, (December 15), NP1-NP22.

Ajzen, Icek and Martin Fishbein (1980), Understanding Attitudes and Predicting Social Behavior, Englewood Cliffs, NJ: Prentice Hall.

Barnett, Homer G. (1953), Innovation: The Basis of Cultural Change, New York: McGraw-Hill.

Bass, Frank M. (1969), "A New Product Growth Model For Consumer Durables," Management Science, 15 (January), 215-227.

Bennett, Stephen (1987), “The Headquarters' View: Its Time to Weed Out the Imposters," Progressive Grocer, (November), 54-71.

Churchill, Gilbert A. Jr., Neil M. Ford and Orville C. Walker Jr. (1992), Sales Force Management, 4th ed., Homewood, IL: Irwin.

Davis, Kenneth R. and Frederick E. Webster Jr. (1968), Sales Force Management, New York, NY: The Ronald Press Company.
Einhorn, Hillel J. and Robin M. Hogarth (1981), “Behavioral Decision Theory: Processes of Judgment and Choice," Annual Review of Psychology, 32, 53-88.

Farris, Paul, James Oliver and Cornelis de Kluyver (1989), "The Relationship Between Distribution and Market Share," Marketing Science, 8 (2), 107-127.

Felgner, Brent H. (1989), "Retailers Grab Power, Control Marketplace," Marketing News, 23, (January 16), 1-2.

Fishbein, Martin and Icek Ajzen (1975), Belief, Attitude, Intention and Behavior: An Introduction to Theory and Research, Reading, MA: AddisonWesley.

Gatignon, Hubert and Thomas S. Robertson (1985), "A Propositional Inventory for New Diffusion Research," Journal of Consumer Research, 11 (March), 849-865.

Granovetter, Mark S. (1973), "The Strength of Weak Ties," American Journal of Sociology, 78 (May), 1360-1380.

Hirschman, Elizabeth C. and Ronald W. Stampfl (1980), "Roles of Retailing in the Diffusion of Popular Culture: Microperspectives," Journal of Retailing, 56 (Spring), 16-36.

Klonglan, Gerald E. and E. Walter Coward Jr. (1970), "The Concept of Symbolic Adoption: A Suggested Interpretation," Rural Sociology, 35 (March), 77-83.

Lambkin, Mary and George S. Day (1989), “Evolutionary Processes in Competitive Markets: Beyond the Product Life Cycle," Journal of Marketing, 53 (July), 4-20.

Mahajan, Vijay and Eitan Muller (1979), “Innovation Diffusion and New Product Growth Models in Marketing," Journal of Marketing, 43 (Fall), 55- 68.

Midgley, David (1974), "Innovation in the Male Fashion Market: The Parallel Diffusion Hypotheses," Proceedings of the 31st ESOMAR Seminar, Barcelona: ESOMAR.

and Graheme R. "Innovativeness: The Dowling Concept (1978), and its Measurement," Journal of Consumer Research, 4 (March), 229-242.

Mittelstaedt, Robert A., Sanford L. Grossbart, William W. Curtis and Stephen P. Devere (1976), “Optimal Stimulation Level and the Adoption Decision Process," Journal of Consumer Research, 3 (September), 84-94. 
Moncrief III, William C. (1986), "Selling Activities and Sales Position Taxonomies for Industrial Sales Forces," Journal of Marketing Research, 23 (August), 266-67.

Rao, Vithala and Edward W. McLaughlin (1989), “Modelling the Decision to Add New Products by Channel Intermediaries," Journal of Marketing, 53 (January), 80-88.

Rink David R. and John E. Swan (1979), "Product LifeCycle Research: A Literature Review," Journal of Business Research, 7 (September), 219-242.

Robertson, Thomas S., Joan Zielinski and Scott Ward (1984), Consumer Behavior, Glenview, IL: Scott, Foresman.

Rogers, Everett M. (1983), Diffusion of Innovations, New York, NY: The Free Press.

Rosen, Dennis L. and Richard W. Olshavsky (1987), “A Protocol Analysis of Brand Choice Strategies Involving Recommendations," Journal of Consumer Research, 14 (December), 440-444.
Saporito, Bill (1991), “Campbell Soup Gets Piping Hot," Fortune, (September 9), 142-48.

Simon, Hermann and Karl-Heinz Sebastian (1987), "Diffusion and Advertising: The German Telephone Campaign," Management Science, 33 (April), 451-466.

Takada, Hirokazu and Dipak Jain (1991), “CrossNational Analysis of Diffusion of Consumer Durable Goods in Pacific Rim Countries," Journal of Marketing, 55 (April), 48-54.

Taylor, Thayer C. (1986), "The Great Scanner Face-Off," Sales and Marketing Management, (September), 43-46.

Tetlock, Philip E. (1991), “An Alternate Metaphor in the Study of Judgment and Choice: People as Politicians," Theory and Psychology, 1 (4),451- 475.

Wind, Jerry and Vijay Mahajan (1987), "Marketing Hype: A New Perspective for New Product Research and Introduction," Journal of Product Innovation Management, 4, 43-49. 


\section{Author Biographies}

Madhavan Parthasarathy is a doctoral student at the University of Nebraska-Lincoln. He received an MBA degree from the University of Wyoming in 1989. His research interests are in the areas of diffusion of innovations and product discontinuance behavior: Articles authored by him have been presented at the AMA Winter Educators' Conference, the Retail Patronage conference and the Macromarketing conference and published in their respective proceedings. He expects to graduate in 1994.

Ravipreet S. Sohi is an assistant professor of marketing at the University of Nebraska-Lincoln. He received an MBA from the University of BombayIndia and an M.S. and a Ph.D. in Marketing from the University of Wisconsin-Madison. He has worked for a number of years in the sales management area with a large multinational organization. His marketing research interests are in the areas of sales management, channels of distribution and marketing strategy.

Ronald D. Hampton is Maurice J. and Alice Hollman College Professor of International Business, University of Nebraska-Lincoln. He is also the director of Graduate and International Programs for the College of Business Administration. Dr. Hampton has published articles and abstracts in such journals as the Journal of Marketing Research, the Journal of Business Research, Journal of the Academy of Marketing Science, Journal of Retailing, and Journal of Personal Selling and Sales Management. His research interests include international trade and distribution, diffusion of innovations and retailing. 